Mestre em Comunicação e Semiótica pela PUC-SP. Especialista em Criação e Styling de Moda (Senac-SP) e em Fashion Imagem (Senac-SP e Istituto Marangoni). Atualmente, é professora na graduação em Moda do Istituto Europeo di Design (IED) e coordenadora dos cursos de pós-graduação em Moda do Senac-SP e do Centro Universitário Belas Artes, em São Paulo. Atua também nas áreas de Consultoria de Imagem, Gestão de Inteligência e Comunicação para empresas do setor de cultura e moda.

E-mail: jooamand a@hotmail.com

\title{
O cinema e a moda: aproximações e distinções
}

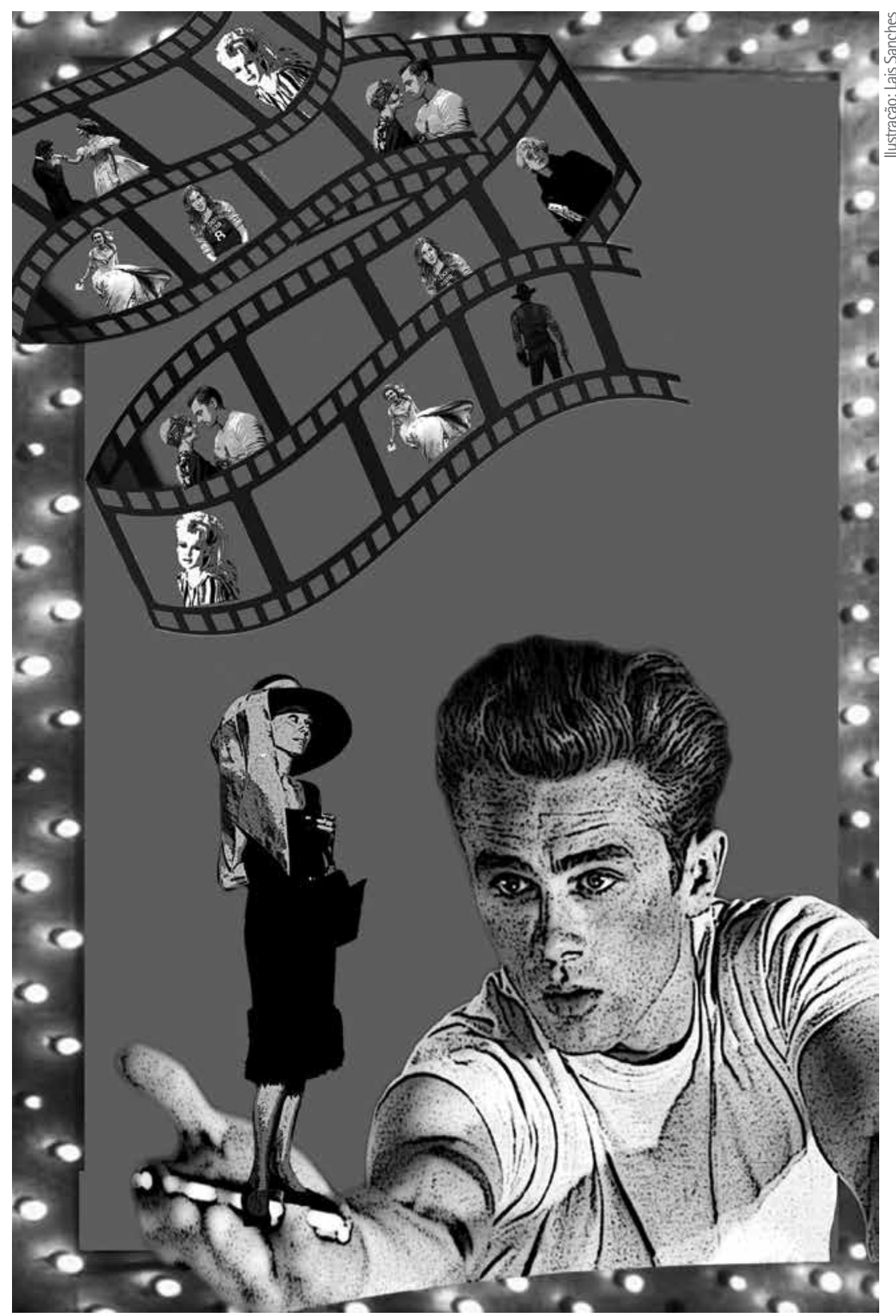

Parte 1

Há uma relação de reciprocidade entre a moda e o cinema: ambos são midiáticos. Trata-se de indústrias que mexem com a sensibilidade das pessoas, além de gerar empregos, estimular o turismo e promover o entretenimento. E tem mais: cinema e moda se influenciam mutuamente. Assim como no cinema, dependendo da época, uma linguagem de moda é determinante para instaurar tendências, estilo e comportamento. 
É bom lembrar que o conceito de moda é sempre mais abrangente do que as roupas tomadas isoladamente. Cultura, mercado, tecnologia, música, dança... Tudo pode virar moda, principalmente o que é som, imagem e espetáculo para as massas.

Assim, a sétima arte já ditava moda quando, desde o início do século $X X$, as muIheres iam ao cinema de caderninho e lápis na mão, para copiar os modelos usados por Greta Garbo, Marlene Dietrich, Joan Crowford, Audrey Hepburn, Lis Taylor, dentre outras. Já nos anos 1960, os jovens copiavam a calça jeans, a camiseta branca, a atitude rebelde e o corte de cabelo de James Jean em Juventude transviada (Nicholas, Ray, 1955). 0 penteado "chucrute" de Brigitte Bardot em EDeus criou a mulher (Roger Vadim, 1956) foi o penteado atualizado na versão de Amy Winehouse. Nos anos 1950, a filmografia do mestre do suspense Alfred Hitchcock funcionava como um belo desfile de moda e, nos anos 1980, o estilista Jean-Paul Gaultier assinava, dentre outros filmes, os figurinos de: Kika (Pedro Almodóvar, 1993) e O quinto elemento (Luc Besson, 1997).

A parceria entre um estilista e uma atriz é também uma excelente estratégia de marketing para gerar visibilidade em torno de uma marca, como aconteceu com a atriz Audrey Hepburn e Givenchy, e Catherine Deneuve e Yves Saint Laurent, nos anos 1980. Para citar um exemplo, no filme Os intocáveis (Brian De Palma, 1987), tendo como inspiração a década de 1930, Giorgio Armani vestiu as personagens de Robert De Niro, Sean Connery e Andy Garcia. Mais recentemente, o filme Avatar (James Cameron, 2009) serviu de inspiração para a última coleção de Alexander McQueen. Essa influência é oxigenada a cada momento, conforme o espírito do tempo. Existem diferenças entre Bonequinha de luxo, de 1961, e o que vem ocorrendo nos últimos anos, com Sexy and the Citye Alice no País das Maravilhas, de Tim Burton. Lembremos de algumas contribuições evidentes do cinema para a moda. Em Bonequinha de luxo, o look "pretinho básico", criado pelo francês Hubert de Givenchy, que até hoje não saiu de moda. Em Sexy and the City, a importância das marcas como orientação ao consumo. Em Alice no País das Maravilhas, de Tim Burton: a contaminação daquele universo lúdico e pangeracional (ou seja, que é pretensamente infantil, mas no fundo se refere à iconografia de todas as idades).

Moda e cinema são duas indústrias que absorvem mão de obra e movimentam o PIB do país. Como numa via de mão dupla, ambas se oxigenam, se regeneram e se traduzem. A moda é mais antiga que a indústria do cinema, claro. 0 cinema só virou moda muito depois que surgiu com os irmãos Lumière. Nas mãos de Georges Méliès, tornou-se espetáculo e agora dita a moda, pelas suas estrelas e pelo modo como ele, enquanto linguagem, consegue traduzir todos os anseios da comunicabilidade humana. 0 filme Avatarinfluenciou a inspiração de formas, cores, texturas e a estampa na coleção primavera-verão de Alexander Mcqueen (2010). Outra influência foi a alusão a Charles Chaplin do filme Tempos modernos (1936) na passarela de John Galliano em sua coleção primavera-verão de 2011, vista através de sua gestualidade, seus movimentos e sua maquiagem. Mais recentemente, temos o desfile da Louis Vuitton (2012), inspirado no filme A invenção de Hugo Cabret, de Martin Scorcese (2011).

0 oposto também acontece, quando o mundo fashion é tema para filmes, fornecendo personagens para o centro da trama, como em Coco Chanel (Anne Fontaine, 2009), Yves Saint Laurent (Jalil Lespert, 2014), ou Valentino: o último imperador (Matt Tyrnauer, 2008). Nos filmes Histórias de ELLE (David Teboul, 2005) e 0 diabo veste Prada (David Frankel, 2006), o mundo das redações de revistas são o acontecimento principal. Já no pseudocumentário A elegante Polly Maggo (William Klein, 1966), a vida de uma modelo americana e sua inclusão do mundo da moda é abordada.

\section{Parte 2}

Segundo Jacques Aumnont, o cinema "pensa", ou seja, inventa histórias, técnicas narrativas, representações humanas, formas de corpo, explora o limite da experimentação e sentimentos. Os sujeitos humanos que o cinema nos apresenta são muitas vezes mitos, como as divas, além de personagens que vão marcando época e que povoam a fantasia ou o cotidiano. Para chegar até as telas, esses sujeitos corpóreos vão marcando seu espaço em signos concretos: a maquiagem, a roupa, os acessórios e o penteado são os primeiros signos que constroem a aparência das personagens a partir do seu aspecto físico. A linguagem visual da personagem no cinema "narra" sempre algo a seu respeito: características sociais, psicológicas, identificação de um tipo histórico, transformação de um estado emocional para outro e caracteristicas do seu caráter. 
0 vestuário é um dos mecanismos de produção de sentido do cinema, um instrumento significativo, cujos signos se convertem e funcionam como unidades linguísticas parecidas com a língua falada e sonora, que são muito importantes para o cinema. Um exemplo é o filme 0 Leopardo (Luchino Visconti, 1963), no qual o vestuário das personagens "fala" durante quase todas as cenas, conseguindo traduzir em imagens profundos sentidos na história. Outro é o filme Confissões de uma garota de programa (Steven Sodenberg, 2009), em que toda a narrativa, não sendo linear, é construída a partir do vestuário da personagem principal.

No cinema, o vestuário "faz crer" por meio do sentido da visão, necessitando de signos para se fazer coerente e dialogar com o movimento da câmera, ou com os diálogos das personagens. Aumont define a ideia de "verossímil" na relação do cinema com a opinião comum e a sua relação com os outros textos e sua função na história que conta. A verossimilhança não está relacionada somente ao cinema realista ou a imagens históricas e sociais representadas, mas à complexidade dos textos culturais com que o cinema contribui para criar.

Tomemos como exemplo a imagem do "cowboy" tal como foi construído no seu aspecto externo e no seu estilo de aparência: chapéu de couro, botas, calça com detaIhes bordados em couro, cinturão com revólver. Qual o realismo presente nessa imagem? Que correspondência existe entre o cowboy do século XIX e a personagem? Os signos presentes na vestimenta do corpo estabelecem uma convenção entre o filme e o espectador. Ou seja, o cowboy tal como aparece nos faroestes nunca existiu de verdade, mas representa uma espécie de acordo implícito entre o filme e o público. Sendo assim, a roupa, a maquiagem, o penteado do cabelo, os acessórios e o cenário se colocam em movimento no cinema criando um plano textual e intertextual. Em outras palavras, o vestuário faz funcionar a fantasia.

\section{Parte 3}

0 desfile de moda presente em $A$ duquesa, filme que ganhou o Oscar de melhor figurino (Saul Dibb, 2008), tem como cenário a Inglaterra em 1774. Naquele tempo, a moda era o motor da economia, tanto no comércio urbano de importação e exportação, como uma forma de ostentar a posição social dentro do país. A vestimenta da época permite detectar a posição das pessoas e conquistar prestígio. Não é fácil definir onde começa e termina o figurino, pois o corpo (gestual, ritmo, postura) e a roupa (íntima ou não), os acessórios (capuz, faixas na cintura, luvas, plumas, chapéus, pelerines, flores, laços, as perucas, a maquiagem e as joias), fazem a composição do arranjo visual da personagem. A materialidade do figurino é a primeira impressão do telespectador e seu primeiro contato com o ator e a personagem. Ou seja, o figurino caracteriza o meio social, época, estilo e preferências individuais, além da localização das ações da personagem, a ponto de transformar seu corpo numa partitura gestual.

As roupas de $A$ duquesa eram estruturadas, com o efeito de rigidez, dignidade e seriedade. Projetando seu corpo para frente com imponência e austeridade, modificando as suas atitudes e gestos. A personagem tinha um discurso político contraditório de igualdade. Seus ideais são liberais (lluminismo), mas o figurino é conservador (aristocrático). Para o telespectador, trata-se de um figurino de época, mas indo além, a personagem da Duquesa promovia um verdadeiro desfile de moda e, como na imprensa atual de celebridades, sua presença em eventos sociais era noticiada pelos jornais. Os desenhistas faziam sua caricatura para os folhetins satirizando as atitudes e a aparência de frivolidade.

Assim, as roupas vão muito além das palavras; no seu silêncio transportam todas as nossas narrativas, memórias e afetividades. Assim, a materialidade da memória afetiva está aprisionada nas nossas roupas.

Igualmente, é importante destacar que o cinema e a moda constituem sistemas de signos, de linguagens, e, como disse Wim Wenders no filme $A$ identidade de nós mesmos (1989), ambos trabalham com a relação entre imagem e identidade. A identidade visual da imagem em movimento e a identidade corpórea da vida cotidiana.

\section{REFERÊNCIA}

